The expenses of the Instituto are not derived from any Brazilian Rockefeller or Carnegie; the funds come about half from the Government and the other half from the sale of vaccines and serums which are made there. Thus the whole thing, from first to last, is to be regarded as a flower of Brazilian civilisation, one of the chief instrumentalities for Brazilian progress. As such, it should be known to the world and to the people of Brazil. As I, the foreigner, went over the building, enthusiastic at what I saw, a longtime resident of Rio also went the rounds, and confessed to us that until that day he never imagined what lay so close at hand. The latest number of the Memorias (vol. I7, part 2) was just being distributed, containing articles on ciliate Protozoa parasitic in guinea-pigs, a revision of the scorpions of Brazil, an account of worms parasitic in birds, and a statistical study of the incidence of disease due to parasitic worms among the children of Paraná. These papers are in Portuguese, but are accompanied by translations into English or French.

The work for which Dr. Chagas is especially well known is that on the disease called opilacao, caused by a trypanosome which is communicated by a large hemipterous bug, the Triatoma megista. The trypanosome was described by Dr. Chagas as Trypanosoma cruzi in 1909. The bugs frequent native houses, flying and attacking at night, as was graphically described to me by Dr. C. Spegazzini when I met him at La Plata. Dr. Chagas showed us the parasites in the fibres of the human heart and in the blood of a dog inoculated with injected human blood. Other species of Triatoma also carry the parasites. Triatoma geniculata gets its trypanosomes from the armadillo, Dasypus novemcinctus. The opilacao disease is not coincident with the distribution of Triatoma. Dr. E. Escomel of Arequipa, Peru, told me that Triatoma infestans was found between Arequipa and Mollendo, but harboured no trypanosomes. He had observed that it was attacked and killed by the spider Lathrodectes mactans, common in that region, as also in North America. Triatoma sanguisuga of the United States once enjoyed newspaper notoriety as the
" kissing bug," but it appears to carry no trypanosomes. There can be little doubt that it would be capable of transmitting Trypanosoma cruzi, were it once infected.

The Instituto has a museum, and a library of 40,000 volumes, in uniform red binding. This is the largest medical library in South America. Behind the main building are smaller ones for physicochemistry and mycology. The department of pathology was started in I9I8 under the direction of Dr. Bowman C. Crowell, now of South Carolina. Dr. Crowell had specialised in tropical diseases in the Philippines, and was able to establish the work at Rio on a thoroughly scientific basis. Reports are now made on all autopsies in the Rio hospitals. Thus the progress and incidence of disease is watched with unceasing vigilance. There is of course a good collection of mosquitoes, including those concerned with malaria and yellow fever, the exact distribution of which is mapped. Mosquitoes are such fragile insects that in many collections, especially when much used, they soon become badly broken. At the Instituto this is avoided by placing them in small tubes, pinned on the cork. Thus they can be examined with a lens, without risk of damage. I regretted not to meet Dr. Adolph Lutz, so well known for his studies of blood-sucking Diptera. He was absent giving a course in parasitology in Venezuela, at the request of the Government of that country.

The museum contains a large collection of Batrachia and of poisonous snakes. Dr. Chagas said that Lachesis is the most dangerous form. Around the room are exhibits to illustrate all the important tropical diseases, some of which are little known to people of other regions. Fleas are important in this connexion: the collection of fleas is now being studied by Mr. Cezar Pinto, who has also described species of leeches. There is a small lecture theatre, and courses in bacteriology, proto-zoology, helminthology and entomology are given for graduate students of medicine. Even fresh-water Mollusca (Planorbis) have received critical attention, on account of the parasites they harbour.

\title{
Recent Researches on the Physiology of the Stomach.
}

$T$ HE large amount of work which has been carried out on the secretory processes and movements of the stomach might suggest that further investigations could add but little to our knowledge ; such is, however, far from being the case. Recent advances made in this subject are due in the main to two quite different lines of approach; the improvement in surgical technique has produced more clear-cut results from animal experiments, and the application of these results to man has been facilitated by the discovery of methods of investigating the physiology of the stomach in human beings, whereby essential information, without which the true significance of animal experiments may be obscure, has been obtained.

As an illustration of the former method of advance, recent work by R. K. S. Lim, A. C. Ivy, and J. E. McCarthy may be cited (Quart. Journ. Exper. Physiol., I925, vol. I5, pp. I3 and 55). The authors, working with dogs, have developed a technique by means of which the entire stomach can be separated from the rest of the alimentary tract; the continuity of the latter is restored by an œsophageo-duodenal anastomosis, while the cut pyloric end of the stomach is made into a permanent fistula, the cardiac end being closed. The animals live well on a diet of ground meat, bread, milk and desiccated pancreas, with unlimited water, but raw meat is passed almost unchanged.
Experiments were also performed on animals provided with different types of stomach pouches and fistulæ, following the original technique of Heidenhain and Pavlov and its various modifications.

Consideration may first be given to the arousal of gastric secretion by stimuli acting on the stomach itself; these are of two types, mechanical and chemical. The authors show unequivocably that mechanical stimulation by distension of the organ or a pouch thereof with a balloon causes a secretion of gastric juice, which occurs not only after severance of the vagus nerves, the main secretory and motor nerves of the stomach, but may be seen also in an isolated fundus pouch when the main stomach is distended, or in the stomach when a pyloric pouch is stimulated. There is a latent period of five to fifteen minutes after the beginning of the distension before secretion appears.

These observations are of great interest, not only because they confirm the opinions of some of the older physiologists, whose views have found little favour in modern teaching, but also because they suggest that certain observations on man, in which a mechanical stimulation has been suspected, are probably to be taken as really due to this cause. Many previous observations have shown that a flow of gastric juice can be obtained by the application of certain sub- 
stances to the mucosa of the stomach; the authors have confirmed these results, showing that raw meat juice, $\beta$-alanine, and histamine stimulate, whereas undigested foods are without effect. The actual mechanism of stimulation is, however, not yet finally settled. The presence of extrinsic nervous connexions is unnecessary, but since a denervated pouch responds to the stimulation of the main stomach, one must assume that the effective stimulus is a chemical agent, carried by the circulating blood.

The authors have been unable to obtain unequivocal evidence of a hormone, such as postulated by Edkins, in the blood, and therefore incline to a view which advocates a common mechanism, as the basis of both mechanical and chemical stimulation. The stimuli produce an increased blood flow through the gastric glands resulting in an increased flow of gastric juice; in the case of mechanical distension, the motility of the stomach is involved in this effect. It is, however, possible that increased blood flow consequent on increased movements due to distension may be concerned only in the effects of mechanical stimulation, whilst the hormone mechanism may explain the results of chemical stimulation, more especially as Ivy reports, in a recent review of the subject, that a gastric pouch transplanted to a mammary gland secretes when gastrin (an extract of gastric mucous membrane) and histamine are applied to the surface of the main stomach, in which case an increased blood flow seems scarcely adequate as an explanation (v. Journ. Amer. Med. Assoc., I925, vol. 85, p. 877). It is to be noted, moreover, that in the case of the secretion of saliva, an increased blood flow through the salivary glands does not produce an increased secretion.

The gastric juice produced by local stimulation of the stomach is only part of that secreted in response to a meal. Before the food enters the stomach secretion occurs, produced reflexly by impulses set up by the sight and smell of the meal, together with those arising from its presence in the mouth itself. The arcs concerned in the latter reflex are situate in the brainstem, since the "psychic" secretion, as it is called, occurs in a decerebrate dog when given food. But Lim, Ivy, and McCarthy have added yet a further period to the secretion of gastric juice by showing that it is aroused by the application of digestion products such as peptone, amino-acids, and amines to the mucosa of the small intestine. If a meal were given to their dog with a pouch of the entire stomach, a secretion of gastric juice occurred about one to three hours later, depending in part on the time for digestion in the small intestine, in part on the time of appearance of the bile, which also acts as a stimulant. Hence gastric secretion can be divided into three phases, a cephalic (or "psychic"), a gastric, and an intestinal. It is only on an accurate knowledge of these processes that a rational therapy of gastro-intestinal tract disease can be based.

A certain amount of doubt has arisen as to the actual nature of the movements in the stomach, chiefly owing to the fact that different types have been described in man and animals; sometimes even different observers have found different appearances in the same species. E. D. McCrea, B. A. McSwiney, J. W. Morison, and J. S. B. Stopford (Quart. Journ. Exper. Physiol., I924, vol. I4, p. 397) have investigated the movements of the stomach in the rabbit, cat, dog, and man, both by means of the X-ray and also, in the animals, by direct inspection of the organ exposed under saline. Their observations clarify and correlate those of previous investigators. The fundus and part of the body of the organ remain almost quiescent during digestion, slowly contracting on the mass of food and forcing it into the more distal parts. In the latter two types of movements occur; in both there is a peristalsis of the remaining part of the body, but in one this is arrested at the pyloric antrum, whilst in the other the wave passes over it and reaches the pylorus; in the former case the peristaltic wave over the body is followed by contraction of the pyloric antrum and canal as a whole, in the same manner as the heart contracts in systole. The first type of movement is predominant in the stomach of the dog, rabbit, and man, the second in that of the cat; but occasionally the opposite type may occur, except that the second has not been observed in the dog's stomach. A transitional form is sometimes seen, namely, ripples running over a tonically-contracted pyloric antrum. The rhythms of the two parts of the stomach may be different. Movements can also be seen in the quiescent part of the fundus in man if the air-cap is displaced and its place taken by the barium sulphate meal. The authors conclude that the variations observed are due to differences in the type and consistence of the food, in the degree of tension in the muscular wall, and in the actual arrangement of the muscular fibres therein in the different species. The research system atises the somewhat confusing observations which have been previously made on this subject.

\section{American Work on Tides. ${ }^{1}$}

\section{T}

HE United States Coast and Geodetic Survey has done useful service in issuing the special publications referred to below. The manual prepared by Mr. Schureman was designed primarily for the tidal computers of the Survey, but the aim was to produce a convenient work of reference on the subject of the harmonic analysis and prediction of tides. It gives a résumé of the work of Kelvin, Darwin, and Harris. Part I. is devoted to the development of the tidegenerating force, to the methods of analysis used by the Survey, and to a description of the U.S.A. tidepredicting machine. The method of analysis is worthy of comment. It makes use of several thousand stencils for the special summations required for the isolation of the constituents. The manual indicates, apparently for the first time, some of the more recent improvements in the method, and these are such as

1 A Manual of the Harmonic Analysis and Prediction of Tides, by P. Schureman; Tides and Currents in New York Harbour, by H. A. Marmer Tides and Currents in San Francisco Bay, by L. P. Disney and W. N Overshiner; A Portable Automatic Tide Gauge, by G. T. Rude. Special Office.) Prices 100, 30, 20, and 10 cents respectively.

No. 2930 , voL. I I 6$]$ to diminish considerably the labour of calculation. In older methods only those constituents of which the speeds are exactly in the ratios I to $2,3,4,6$ and 8 , were treated together until the final processes of the analysis were reached, but in this method constituents the speeds of which are approximately in these ratios are treated together in the earlier stages of the summations, and "secondary stencils" are then used to isolate the respective constituents.

Parts II. and III. are most useful to computers and research workers in other countries. Part II. contains tables of standard functions used in analysis and prediction, Harris's tables having been extended and others added. The astronomical arguments are now given from 1850 to I999. Part III. consists of a noteworthy list of harmonic constants for nearly a thousand places scattered throughout the world. Hitherto research workers have had difficulty in obtaining lists of such constants, and no such comprehensive list has ever been published, though no doubt several manuscript lists have existed. The Survey has received constants from many sources 